\title{
AVALIAÇÃO DA COMPOSIÇÃO QUÍMICA E ATIVIDADE ANTIOXIDANTE DOS EXTRATOS E FRAÇÕES DE FOLHA DE LUETZELBURGIA AURICULATA (ALEMÃO) DUCKE
}

\author{
Byanka Silva Sena ${ }^{1}$; Angélica Maria Lucchese ${ }^{2}$ \\ 1. Bolsista PIBIC/CNPq, Graduando em Farmácia, Universidade Estadual de Feira de Santana, e-mail: \\ byankasena8@gmail.com \\ 2. Orientador, Departamento Dexa, Universidade Estadual de Feira de Santana, e-mail: \\ angelica.lucchese@gmail.com
}

PALAVRAS-CHAVE: Atividade antioxidante; compostos fenólicos; perfil cromatográfico.

\section{INTRODUÇÃ̃O}

Luetzelburgia auriculata (Allemão) Ducke é uma leguminosa típica do Brasil e predominantemente encontrada na região Nordeste. É popularmente conhecida como pau-mocó e pertence à família Fabaceae, subfamília Papilionoideae. De suas raízes, nos períodos de seca se retira fécula, usada excepcionalmente para a alimentação humana, pela sua ampla distribuição na caatinga (QUEIRÓZ, et al., 2013).

Quanto à composição química, além das saponinas, foi identificado nas sementes de $L$. auriculata a presença de alcaloides e flavonóides. Extratos da folha apresentaram forte atividade antimicrobiana, mostrando-se ativos contra bactérias Gram-positivas (Staphylococcus aureus). A partir da avaliação do potencial citotóxico dos extratos pelo método do MTT, o extrato acetato de etila na raiz e hexânico nas folhas, mostraram alta atividade citotóxica contra linhagens humanas de câncer de pulmão, cólon e laringe na concentração (VASCONCELOS, 2012). Assim, estes dados contribuem com os estudos científicos acerca desta espécie, que mostra-se como promissora fonte de biomoléculas com importantes atividades.

Assim, objetiva-se aprofundar nesta espécie o potencial dessa ação para ser usada em fins terapêuticos, bem como avaliar sua composição química.

\section{MATERIAL E MÉTODOS OU METODOLOGIA (ou equivalente) COLETA}

A espécie foi coletada no estado da Bahia, e uma exsicata foi depositada no Herbário da UEFS para identificação.

\section{OBTENÇÃO E PROCESSAMENTO DOS EXTRATOS BRUTOS}

As folhas forão secas à temperatura ambiente e pulverizadas em moinho de facas. A extração foi realizada por maceração com metanol e o solvente removido por destilação a pressão reduzida com auxílio de um rotaevaporador.

\section{PROCESSAMENTO DOS EXTRATOS BRUTOS}

O extrato metanólico das folhas foi fracionado por partição líquido-líquido para obtenção das frações. Para isso $20 \mathrm{~g}$ do extrato metanólico bruto será ressuspenso em metanol:água $(7: 3 \mathrm{v} / \mathrm{v})$ e extraído com clorofórmio para obtenção das frações clorofórmica e hidrometanólica, visando uma semi-purificação das substâncias através 
de suas polaridades. $\mathrm{O}$ solvente das frações foi removido em evaporador rotatório, sob pressão reduzida, em temperaturas de $40-45^{\circ} \mathrm{C}$ e o resíduo de solvente foi retirado por evaporação em capela de exaustão.

\section{DETERMINAÇÂO DO PERFIL CROMATOGRÀFICO POR CROMATOGRAFIA LÍQUIDA DE ALTA EFICIÊNCIA}

O perfil cromatográfico dos extratos brutos e das frações das folhas, foi determinado por cromatografia líquida de alta eficiência, segundo Sá et al. (2012).

\section{DETERMINAÇÃO DO PERFIL CROMATOGRÁFICO POR CROMATOGRAFIA EM CAMADA DELGADA}

O perfil cromatográfico foi determinado em cromatografia em camada delgada com o emprego de reveladores químicos para a detecção das classes de metabólitos, como terpenos e esteroides, flavonoides, cumarinas, triterpenos, entre outros, conforme Wagner e Bladt (1995).

\section{DETERMINAÇÃO DA ATIVIDADE ANTIOXIDANTE}

A atividade antioxidante foi avaliada pelos métodos de sequestro de radical difenilpicrilhidrazila (DPPH), co-oxidação do ácido linoleico/B-caroteno, conforme Sá et al (2012) e Re et al. (1999), empregando espectrofotometria no UV-VIS.

\section{DETERMINAÇÃO DO TEOR DE COMPOSTOS FENÓLICOS E FLAVONOIDES}

O conteúdo fenólico total foi determinado através do método espectrofotométrico de Folin-Ciocalteau (Peres et al., 2009). O teor de flavonóides do extrato metanólico foi determinado por espectrofotometria no UV-VIS, utilizando o cloreto de alumínio $\left(\mathrm{AlCl}_{3}\right)$ para possibilitar a quantificação (Banov et al., 2006).

\section{RESULTADOS E/OU DISCUSSÃO (ou Análise e discussão dos resultados)}

A massa de material vegetal seco da espécie Luetzelburgia auriculata (Alemão) Ducke utilizada foi de 190,30 g para a realização da obtenção e processamento dos extratos brutos, e foi obtido 53,64 g de extrato bruto, tendo rendimento de 24,08\%. Após o fracionamento, a massa da fração clorofórmica obtida foi de 3,8378g, assim o seu teor extrativo após calculado foi de 19,18\% para o solvente clorofórmio.

Para a análise cromatográfica em camada delgada(CCD) com o revelador LiebermannBurchard apresentou resultado positivo quando observado na luz UV na amostra. Com o revelador Anisaldeído houve o aparecimento de coloração violeta indicando presença de terpenos e esteroides. O teste com revelador para cumarina mostrou-se negativo.

Por não eluir em hexano foi possível concluir que a espécie continha compostos com polaridade maior e por isso foi feito testes com solventes mais polares até chegar àquele que melhor separasse os compostos. O sistema de solvente que apresentou melhor resultado foi a mistura contendo $100 \mathrm{~mL}$ de acetato de etila, $13,5 \mathrm{~mL}$ de metanol e 10 $\mathrm{mL}$ de água, o qual apresentou bandas características e bastante destacadas e que possibilitou a revelação da placa. Os fatores de retenção das bandas cromatográficas reativas a ácido sulfúrico em $\mathrm{cm}$ foram: 0,$10 ; 0,15 ; 0,19 ; 0,24 ; 0,31 ; 0,56$ e 0,81. Os fatores de retenção em $\mathrm{cm}$ das bandas com resultados positivos para reagente NP/PEG, foram: 0,$07 ; 0,12 ; 0,16 ; 0,21 ; 0,28 ; 0,33 ; 0,55$ e 0,73 . 
Os teores de fenólicos totais e flavonóides totais da espécie Luetzelburgia auriculata (Alemão) Ducke estão expressos na tabela 1 abaixo:

Tabela 1:Teor de fenólicos totais expresso em equivalente de ácido gálico e teor de flavonóides totais expresso em equivalente de quercetina de Luetzelburgia auriculata (Alemão) Ducke.

\begin{tabular}{ccc}
\hline & Teor de fenólicos & Teor de flavonóides \\
\hline Extrato metanólico & $164,67 \mathrm{mgEAG} / \mathrm{g} \pm 6,66$ & $81,07 \mathrm{mgEQ} / \mathrm{g} \pm 4,81$ \\
Fracão clorofórmica & $80,75 \mathrm{mgEAG} / \mathrm{g} \pm 3,00$ & $110,85 \mathrm{mgEQ} / \mathrm{g} \pm 6,78$ \\
\hline
\end{tabular}

Como pode se observar a fração clorofórmica apresentou um menor teor de fenólicos, o que é explicada devido a baixa polaridade do solvente, no entanto uma quantidade bem maior de flavonóides. Apesar dos compostos fenólicos, que incluem os flavonoides, possuírem grupamentos polares na molécula e, portanto terem uma afinidade maior pela fração hidrometanólica por serem mais polares, observou-se a presença de uma quantidade mais elevada dos flanonóides na porção clorofórmica. Isso pode ser explicado pela possibilidade destes flavonóides serem do tipo aglicona ou metoxilados, o que irá conferir uma menor polaridade à molécula, e uma maior afinidade pela fração clorofómica.

A atividade antioxidante foi avaliada pelos métodos de sequestro de radical difenilpicrilhidrazila (DPPH). Esse radical, de coloração púrpura, absorve radiação UV a um comprimento de onda de $517 \mathrm{~nm}$. Quando é reduzido por um antioxidante (AH) ou uma espécie radicalar $(\mathrm{R} \bullet)$ forma o composto 2,2-difenil-1-picril-hidrazina que apresenta coloração amarela, com conseqüente decréscimo da absorbância (SOUSA et al., 2007).

O excesso de radicais livres é combatido por antioxidantes, sejam eles endógenos ou exógenos, absorvidos na dieta. Dentre os antioxidantes exógenos, destacam-se os compostos fenólicos, principalmente os flavonoides, oriundos de produtos naturais. Por apresentarem ressonância após atuarem no combate aos radicais livres, os compostos fenólicos possuem uma determinada estabilidade, que os permite reter o elétron desemparelhado sem causar danos às estruturas celulares (Barreiros et al., 2006; Soares, 2002).

A atividade antioxidante do extrato metanólico, expressa através do $\mathrm{CE}_{50}$, foi de 446,71 $\mu \mathrm{g} / \mathrm{mL}$, enquanto dos controles positivos foi de $12,05 \mu \mathrm{g} / \mathrm{mL}$ para o Trolox e de 10,11 $\mu \mathrm{g} / \mathrm{mL}$ para o ácido ascórbico (Tabela 3). Analisando estes dados podemos sugerir que embora a espécie possua compostos com ação antioxidante, a concentração mais elevada para sequestrar 50\% dos radicais livres de DPPH indica sua baixa eficácia. Outras espécies da mesma família Fabaceae apresentaram valores de $\mathrm{CE}_{50}$ menores, como exemplo do extrato metanólico das folhas da espécie Bauhinia ungulata L, com $\mathrm{CE}_{50}$ de 20,84 $\mu \mathrm{g} / \mathrm{mL} \pm 0,73$ (PAULA, 2014).

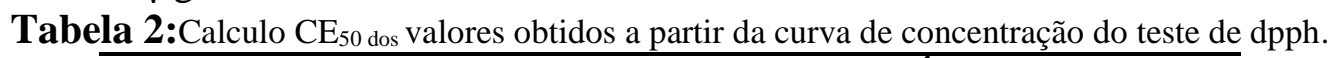

$\begin{array}{ccc}\begin{array}{c}\text { Luetzelburgia } \\ \text { Auriculata }\end{array} & \text { Trolox } & \text { Ácido ascórbico }\end{array}$

$$
446,71 \mu \mathrm{g} / \mathrm{mL} \pm 8,05 \quad 12,05 \mu \mathrm{g} / \mathrm{mL} \quad 10,11 \mu \mathrm{g} / \mathrm{mL}
$$

Os ensaios de atividade antioxidante para as frações provenientes deste extrato, está em andamento, para se avaliar se o fracionamento levou a uma seleção de metabólitos mais ativos.

\section{CONSIDERAÇÕES FINAIS (ou Conclusão)}


No extrato metanólico das folhas de Luetzelburgia auriculata foi detectada a presença de terpenos, esteroides e compostos fenólicos com potencial atividade antioxidante, embora pouco expressiva frente a controles positivos. A determinação da atividade antioxidante das frações clorofórmica e hidrometanólica está em andamento.

\section{REFERENCIAS}

BANOV, D. et al. Caracterização do extrato seco de Ginkgo biloba L. em formulações de uso tópico. Acta Farm. Bonaerense v. 25, n. 2, p. 219-224, 2006.

BARREIROS A. L. B. S. , DAVID J. M. , DAVID J. P. Estresse oxidativo: relação entre geração de espécies reativas e defesa do organismo. Quim Nova., v. 29, n.1, p.113-23, 2006

PAULA, C. S. Potencial antioxidante in vitro das folhas da Bauhinia ungulata L. Rev Ciênc Farm Básica Apl., v. 35, n.2, p.217-222, 2014.

PERES, M. T. L. P. et al. Estudos químicos e biológicos de Microgramma vacciniifolia (LANGSD. \& FISCH.) COPEL (Polypodiaceae). Quim. Nova v. 32, n.4, p. 897-901, 2009.

QUEIRÓZ, Bárbara de S. Caracterização morfológica da semente de luetzelburgia auriculata (fabaceae). In: 64 CONGRESSO NACIONAL DE BOTÂNICA, 2013, Belo Horizonte: UFC, 2013.

RE, $\mathrm{R}$ et al. Antioxidant activity applying an improved ABTS radical cation decolorization assay. Free Radic Biol Med. v. 26, n. 9-10, p.1231-7, 1999.

SÁ, PGS et al Fenóis totais, flavonoides totais e atividade antioxidante de Selaginella convoluta (Arn.) Spring (Selaginellaceae). Rev Ciênc Farm Básica Apl., v. 33, n. 4, p. 561-566, 2012.

SOARES, S. E. Ácidos fenólicos como antioxidantes. Rev Nutr.,v. 15, n.1, p.71-81, 2002.

SOUSA, C. M. M. et al. Fenóis totais e atividade antioxidante de cinco plantas medicinais. Quim. Nova. v. 30, n. 2, p. 351-355, 2007

WAGNER, H.; BLADT, S. Plant Drug Analysis: a thin layer chromatography atlas. Berlin: Springer Verlag, 1995. 384p

VASCONCELOS, Alan Lucena de. PERFIL ANATÔMICO, FITOQUÍMICO, ANTIMICROBIANO E CITOTÓXICO DE Luetzelburgia auriculata (Allemao) Ducke, Recife, 2012. 